\title{
PLUS highway network analysis: case of in-coming traffic burden in 2013
}

\begin{abstract}
PLUS highway is the largest concessionary in Malaysia. The study on PLUS highway development, in order to overcome the demand for efficient road transportation, is crucial. If the highways have better interconnected network, it will help the economic activities such as trade to increase. If economic activities are increasing, the benefit will come to the people and state. In its turn, it will help the leaders to plan and conduct national development program. In this paper, network analysis approach will be used to study the in-coming traffic burden during the year of 2013. The highway network linking all the toll plazas is a dynamic network. The objective of this study is to learn and understand about highway network in terms of the in-coming traffic burden entering to each toll plazas along PLUS highway. For this purpose, the filtered network topology based on the forest of all possible minimum spanning trees is used. The in-coming traffic burden of a city is represented by the number of cars passing through the corresponding toll plaza. To interpret the filtered network, centrality measures such as degree centrality, betweenness centrality, closeness centrality, eigenvector centrality are used. An overall centrality will be proposed if those four measures are assumed to have the same role. Based on the results, some suggestions and recommendations for PLUS highway network development will be delivered to PLUS highway management.
\end{abstract}

Keyword: PLUS highway; In-coming traffic burden; Network analysis; Highway network 